\title{
A Survey on Routing Protocols for MANET
}

\author{
Naman Patel \\ Student, DJ Sanghvi college of \\ Engineering
}

\author{
Akshay Pawar \\ Student, DJ Sanghvi college of \\ Engineering
}

\author{
Narendra Shekokar, Ph.D \\ H.O.D, DJ Sanghvi college of \\ Engineering
}

\begin{abstract}
MANETs or the Mobile Ad hoc Networks are a type of computer networks that have mobile devices, self-configured functioning, no static infrastructure and a wireless medium of information sharing. Rapid increase in demand for cellular phones and laptops that use MANETs has been encouraging extensive research in various optimized routing protocols for MANETs during the past decade. The need for better speed and efficiency in these mobile devices keeps rising every year and the resulting demand for further protocol optimization is seen. The basis of the review is to study all the protocols that have been proposed.
\end{abstract}

\section{Keywords}

AODV, DSR, DSDV, MANET, routing protocols.

\section{INTRODUCTION}

MANETs or Mobile Ad hoc networks have computers, routers or nodes that are moveable such that the network topology alters randomly with respect to time. They have the capacity of self-configuration as after every time interval, the situation of the network is often different. MANETs are largely wireless based networks and hence need special routing protocols that dynamically route packets throughout the network. There are some special challenges in MANETs more than any other networks. The mobility of the nodes has proposed various challenges on the efficiency of the network. Routing in particular has become a difficult task as the routing tables created at one point become insignificant at the immediate next second as nodes change their positions and hence their 'Manhattan distances' randomly without any specific pattern. The traditional routing protocols like DVR have proved futile on MANETs. Various routing protocols therefore have been proposed and implemented specifically for MANET. There are two types of routing protocols: Proactive and Reactive.

\subsection{Proactive Protocols}

These protocols always maintain up-to-date information of routes from each node to every other node in the network. These protocols continuously learn the topology of the network by exchanging topological information among the network nodes. Thus, when there is a need for a route to a destination, such route information is available immediately [1]. One popular protocol that follows proactive approach is DSDV.

\subsection{Reactive Protocols :}

Only the paths that need current connection for communication have their routes ready. Overhead is reduced as every route is separately searched only when needed. Rapidly changing wireless network topology may break active route and cause subsequent route search [4]. Popular protocols that use reactive approach are AODV, DSR.

\subsection{DSDV}

Routes to all nodes in the network are discovered in advance .Every node store one or more routing table (which contains the information about all the available destination \& no. of intermediate nodes) which is broadcast after a fixed interval of time independent of any route changes or not[2]. It was developed by C. Perkins and P.Bhagwat in 1994. Each packet is given a sequence number which could be odd or even depending on whether the link is present or not [3].

\subsection{AODV}

It was developed in Nokia Research Center, University of California, Santa Barbara and University of Cincinnati by C. Perkins, E. Belding-Royer and S. Das. The Ad hoc OnDemand Distance Vector (AODV) routing protocol is intended for use by mobile nodes in an ad hoc network. It offers quick adaptation to dynamic link conditions, low processing and memory overhead, low network utilization, and determines unicast routes to destinations within the ad hoc network. It uses destination sequence numbers to ensure loop freedom at all times (even in the face of anomalous delivery of routing control messages), avoiding problems (such as "counting to infinity") associated with classical distance vector protocols [5].

\subsection{DSR}

The Dynamic Source Routing protocol (DSR) by Johnson Broch 1999 is a simple and efficient routing protocol designed specifically for use in multi-hop wireless ad hoc networks of mobile nodes [6]. It is similar to AODV in that it forms a route on-demand when a transmitting node requests one. However, it uses source routing instead of relying on the routing table at each intermediate device.

In this paper, Section 1 introduces the basis of conducting this review. In Section 2, we review the analysis of the protocols like DSDV, AODV and DSR through parameters such as energy consumption, average throughput, average end to end delay and packet delivery ratio. We also talk about our observations on various aspects in reactive and proactive protocols. We eventually determine which of the protocols discussed are better and the reasons for the same. Section 3 briefly concludes the paper and Section 4 predicts a possible research scope in the future. In the above discussed protocols, DSDV being the proactive protocols has its share of disadvantages but doesn't have an excessive overhead. AODV and DSR are better as a result of their reactivity, but have a higher overhead.

\section{ANALYSIS OF THE PROTOCOLS}

The protocols can be compared on the basis of their simulation outcomes on various parameters. Energy consumption is a parameter that measures that physical energy/electrical energy consumed by a network when the particular protocol runs. The network throughput is the rate of successful message delivery over a communication channel. End top end delay refers to the time taken for a packet to reach from source to destination while Packet Delivery Ratio is the ratio of total packets delivered and the total packets produced. 


\subsection{Energy Consumption:}

On demand routing protocols (DSR, AODV) consume more energy as compared to table driven protocol (DSDV). DSR performs better than AODV although uses source routing. In our opinion, it could be due to caching mechanism used in DSR which reduces the discovery routes overhead. The energy consumption due to routing overhead of DSR is negligible as compared to AODV [7].

\subsection{Average Throughput:}

Average Throughput increases quickly for DSR with increased number of nodes (node speed is $15 \mathrm{~m} / \mathrm{s}$ ). It is observed that performance of AODV improves with increase in number of nodes because nodes become more stationary with speed $15 \mathrm{~m} / \mathrm{s}$ will lead to more stable path from source to destination. DSDV performance dropped as number of nodes increase because more packets dropped due to link breaks. When the number of nodes is greater than 20, AODV shows the better average throughput characteristic than DSR [2].

\subsection{Average End to End Delay:}

On an average DSDV clearly shows that it has less average delay. DSDV performance is pretty stable. The reason may be that it is a table driven protocol, so a node does not need to find a route before transmitting packets. So the delay is fairly stable. From the simulation it can be evidently noticed that reactive protocol AODV and DSR outperforms the pro-active protocol DSDV. AODV generates higher overhead as it used network-wide flooding for route discovery.

\subsection{Packet Delivery Ratio (PDR):}

Performance of the DSDV is reducing regularly while the PDR is increasing in the case of DSR and AODV. AODV is better among the three protocols [8].

In the table given below, we have discussed the observable differences between reactive and proactive protocols. This is crucial to decide between DSDV and AODV/DSR.

Table 1: Comparison between reactive and proactive protocols

\begin{tabular}{|l|l|l|}
\hline Parameters & $\begin{array}{l}\text { Proactive } \\
\text { routing } \\
\text { protocols }\end{array}$ & $\begin{array}{l}\text { Reactive } \\
\text { routing } \\
\text { protocols }\end{array}$ \\
\hline Routing approach & Mostly flat & Flat \\
Traffic & High & Low \\
\hline Periodic & $\begin{array}{l}\text { Required } \\
\text { always } \\
\text { Updates }\end{array}$ & $\begin{array}{l}\text { Not } \\
\text { Required }\end{array}$ \\
\hline Route & $\begin{array}{l}\text { Always } \\
\text { available }\end{array}$ & $\begin{array}{l}\text { Calculated } \\
\text { On demand }\end{array}$ \\
\hline Availability & $\begin{array}{l}\text { Upto } 100 \\
\text { nodes }\end{array}$ & $\begin{array}{l}\text { More than } \\
100 \text { nodes }\end{array}$ \\
\hline Delay & Average to & Average to \\
\hline
\end{tabular}

\begin{tabular}{|l|l|l|}
\hline & low & high \\
\hline Routing information & $\begin{array}{l}\text { Saved in } \\
\text { tables }\end{array}$ & Not saved \\
\hline Storage requirement & Higher & $\begin{array}{l}\text { Route } \\
\text { dependent }\end{array}$ \\
\hline
\end{tabular}

It is observed that in spite of the greater delay in reactive protocols, they prove to be advantageous for MANETs as the on-demand approach complements the dynamic nature of the network.

Amongst the reactive protocols, AODV proves to be better in greater number of nodes while DSR proves to be better in smaller number of nodes. AODV proves to be better due to its internal caching mechanism. The internal caching mechanism allows it to save recently used routes, which in case of no change in the network, can be directly used, hence saving time for recompilation of new routes.In larger number of nodes, a sub-network in a large network doesn't always change with time, hence the cached routes are repeatedly used saving the times for computing new routes. However, an invention of a protocol that services both the ends covered by AODV and DSR is still in question. While research has been extensively made, a completely satisfactory protocol's advent is awaited.

\section{CONCLUSION}

We have therefore discussed significant protocols in MANETs. Their performance through parameters like throughput, end to end delay, energy consumption and packet delivery ratio are reviewed. Based on the outcomes, we have made our judgments on the same

\section{FUTURE SCOPE}

Research on a reactive routing protocol that serves well for larger number of nodes as well as smaller number of nodes can be a future project. Having a satisfactory protocol for MANETs is essential as the demand for better efficiency in MANETs keeps rising exponentially.

\section{ACKNOWLEDGEMENTS}

We humbly thank Dr Narendra Shekokar, the Head of the Department, Computers for agreeing to be the co-author and enriching our research with his extensive knowledge and experience. We also thank our college D J Sanghvi College of Engineering for providing the resources required for research.

\section{REFERENCES}

[1] Boukerche, B. Turgut, N. Aydin, M. Z. Ahmad, L. Bölöni, and D.Turgut, "Routing protocols in ad hoc networks: A survey," "Elsevier Computer Networks", 55 (2011) 3032-3080.

[2] Veena Anand, Suresh Chandra Gupta, "Performance of AODV, DSR and DSDV Protocols under varying node movement", 2012 World Congress on Information and Communication Technologies.

[3] Perkins and P.Bhagwat, "Highly Dynamic Destination Sequenced Distance Vector Routing for Mobile Computers", 7th international conference on Ad-hoc, Mobile and Wireless Networks, 1994.

[4] Mario Joa-Ng, "A Peer-to-Peer Zone-Based Two-Level Link State Routing for Mobile Ad Hoc Networks", IEEE Journal on selected areas in communications, Vol. 17, No. 8, Aug-1999. 
[5] Perkins, E. Belding-Royer and S. Das, "Ad hoc OnDemand Distance Vector (AODV) Routing”, 2003.

[6] David B. Johnson, David A. Maltz, Josh Broch, "DSR: The Dynamic Source Routing Protocol for Multi-Hop Wireless Ad Hoc Networks", 2003.

[7] Ashish Kumar, M. Q. Rafiq, Kamal Bansal, “ Performance Evaluation of Energy Consumption in MANET", International Journal of Computer
Applications (0975 - 8887) Volume 42- No.2, March 2012.

[8] Pankaj Rohal, Ruchika Dahiya, Prashant Dahiya, "Study and Analysis of Throughput, Delay and Packet Delivery Ratio in MANET for Topology Based Routing Protocols (AODV, DSR and DSDV)", INTERNATIONAL JOURNAL FOR ADVANCE RESEARCH IN ENGINEERING AND TECHNOLOGY, Vol. 1, Issue II, Mar. 2013 ISSN 2320-6802. 